\title{
Effective Beneficiation of Low Grade Iron Ore Through Jigging Operation
}

\author{
B. Das*, S. Prakash, S.K. Das and P.S.R. Reddy \\ *Address for correspondence: Scientist, Institute of Minerals and Materials Technology \\ (Council of Scientific and Industrial Research) \\ Bhubaneswar-751013, Orissa, INDIA,Email: bdas@immt.res.in
}

\begin{abstract}
The effectiveness of jigging operation for the beneficiation of low-grade iron ore deposits of Orissa, India has been investigated. Iron ore sample obtained from Barbil region of Orissa containing very high amount of silica and alumina was crushed using the laboratory jaw crusher and roll crusher to prepare different particle sizes. The sink and float tests were carried out to evaluate the possible response of the sample by gravity concentration technique. The samples were subjected to jigging in a laboratory Denver mineral jig and Harz jig. The operating variables used to determine the effectiveness of jigging include, particle size, velocity of water and amplitude. Recovery of iron values and the separation efficiency were assessed by determining mineralogy and the percentages of $\mathrm{Fe}$ in the jig concentrate and tailings by wet chemical and X-ray floroscence (XRF) techniques. Optimum iron ore recovery of $78.6 \%$ was achieved with $63.7 \% \mathrm{Fe}$ in concentrate when the jig was operated at medium stroke, with an average water velocity and at a particle size of below $5 \mathrm{~mm}$. The results are very close to theoretical results obtained by sink and float studies.
\end{abstract}

Keywords: Low grade iron ore, mineralogy, jigging, particle size, water rate, separation efficiency.

\section{INTRODUCTION}

Large numbers of iron ore mines are in operation in Orissa, India to meet the internal and export demand of iron ore for iron and steel making. During the process of mining relatively lower grade iron ore containing $56-58 \% \mathrm{Fe}$ is also being generated and stockpiled separately due to less market and industrial value. The accumulation of these lower grade lumps and fines are increasing day by day due to increase in the regular production of iron ore for steel industries. Simple washing of these low grade ores by scrubbing could not upgrade the iron content as evidenced from some laboratory studies. However the utility of these ores in sinter or pellet making have urged many laboratories in India to undertake systematic studies for recovering iron values from these low-grade ores. 
Lot of developments in iron ore processing have been taken place in recent years in many iron ore producing countries of the world. The emphasis was on development of a cost effective flow sheet to beneficiate the low-grade iron ores to produce concentrates suitable for blast furnace, sinter or pellet making. Some of the development features in the processing side are jigging, innovations in spiral concentrator, autogenous grinding, column flotation, high gradient magnetic separators (HGMS), fine screening etc. Jigging is a gravity-separation technique, where bulk materials are separated into light fraction, medium-density fraction and heavy-density fraction. It is one of the oldest methods of gravity concentration technique. Even today it is the widespread technology in coal preparation because of its high separation precision, cost-effectiveness and high throughput rate [1-2]. It is a technique where particles of mixed bed, size, shape and specific gravity are separated from each other by the force of gravity with stratification. In this process, the close size range feed with correct water balance and pulp density is very much essential. The jigging technology uses water as the separation medium and can be applied to minerals, ores, slags as well as any other material that has difference in density between the wanted and unwanted materials. It is highly effective in the cases where the difference in cut density is more than $4.1 \mathrm{~g} / \mathrm{cc}$. During the last one decade, jigging has become one of the most cost-effective methods of obtaining minerals from solid waste materials [3]. The mechanical separation of plastics such as polystyrene (PS), acrylonitrile butadiene styrene (ABS), and polyethylene terephthalate (PET)] used in copy machines were carried out using a TACUB jig. Under the suitable conditions grades of $99.8 \%$ PS, $99.3 \% \mathrm{ABS}$, and $98.6 \%$ PET were recovered as the products [4]. The effective separation of iron ore concentrate from Itakpe iron ore was achieved by jigging operation. The performance of the jig was greatly influenced by the operating variable of the jig and the particle size of the feed [5]. The recovery of metal values from ferrochrome slag by jigging has been carried out in a commercial plant at Bamnipal, India [6]. In another investigation, the Yang Jig technology offers the recovery of metals from slag, especially from ferroalloys. A commercial Jig plant has been installed in South Africa to recover metal concentrate of $97 \%$ grade with $76 \%$ metal recovery [7]. The upgrading of ferrous ores by jigging has been an emerging trend in South Africa as well as in other countries such as Australia and Brazil. Studies carried out at the Sishen iron ore mine in South Africa have proved that the separation of fine ferrous ores was achieved by Bateman Jig. The new enhanced jig minimizes the back mixing of fine concentrate with reject before discharge. It has been stated that the flow of water inside the jig has a strong bearing on the rate of stratification of particles. Besides that amplitude, frequency of pulsation and feed characteristics are the most important process parameters in jigging [8]. This is permissible because jigging could also be viewed as a repetitive process of fluidization and defluidization which takes place under rapid rate of change of water velocity [9-10].

If ore contains appreciable amount of sulphide minerals, these should be removed by froth flotation prior to gravity concentration. Jigging is widely used for ores and minerals where flotation is not effective and for treating large volume material and for economic reasons where situation detects the least expenditure of money. Jigs are cheap to operate, easy to assess and inspection but require much water. Since the fines are not treatable in jigs, they do not provide a complete solution of any mineral dressing problem. 
Barsua iron ore mine in India has adopted Remco Jigs for beneficiation of lowgrade iron ore fines. Bateman's Apic jig is being used in iron ore mines of South Africa and has demonstrated how the technology is suitable for the separation of fine ferrous ores. A Batac jig is installed to reduce alumina content of iron ore fines from Noamundi mines by M/s Tata Steel. Jigging of iron ore fines was also taken up as the first choice in IMMT, Bhubaneswar to upgrade the iron content from the low-grade fines. The mineralogical characterization of Barbil area iron ore shows that it contains mainly hematite and goethite and minor amounts of kaolinite, gibbsite and quartz. Wide difference in specific gravities of the minerals gives sound basis for adopting the gravity concentration technique. In this study, the effectiveness of gravity techniques for concentrating iron ore of selected size range was investigated using the jigging techniques. The effect of operating variables on the recovery of iron ore using the laboratory Denver mineral jig and Harz jig were evaluated.

\section{EXPERIMENTAL}

A low-grade iron ore sample of Barbil region of Orissa was obtained for detail studies. The as received hematite samples was thoroughly mixed and representative sample was drawn by conning and quartering method for different characterization, mineralogical and beneficiation studies. The size analysis of the representative sample was carried out by wet sieving method. The complete chemical analysis of the bulk sample and different size fractions obtained from the size analysis studies were determined by wet chemical and X-Ray Florescence Technique (XRF). The closed size fractions for experimental studies were prepared by stage crushing in laboratory jaw and roll crusher.

The sink and float studies of different size fractions at three different sp. gravities viz. 2.8, 3.1 and 3.3 were carried out using the heavy organic liquid to separate the liberated light gangue minerals. The sink and float studies of all the size fractions obtained by wet sieving were carried out except the fraction of below 100 micron due to fine nature of the material. All the sink and float products were thoroughly washed with acetone, dried, weighed and subjected to complete chemical analysis.

A Denver mineral jig fitted with screen was used for the jigging studies. The cross sectional area of the jig is $10.5 \times 14.8 \mathrm{~cm}$. It has adjustable stroke lengths with a hutch which convincingly maintains pulsation of water flow for effective separation of light and heavies. The different sized material was prepared by stage crushing in a laboratory roll crusher of different set gaps followed by screening at the desired size. The effects of water velocity and particle size on jigging were studied using different sizes of iron ore of $-5+1 \mathrm{~mm},-4+1 \mathrm{~mm}$ and $-1+0.21 \mathrm{~mm}$. The objective of the study was to achieve better grade and recovery with respect to iron values at any of the sizes. All the jigging tests were carried out in a continuous mode. A vibrating feeder was used to feed the ore to the jig and water was added to the hutch through a controlled water valve and flow meter. Each test was carried out for 15 minutes at a feed rate of $60 \mathrm{~kg} / \mathrm{hr}$. The sample was collected after allowing the jig to stabilize for a period of 5 minutes. The effect of water velocity, stroke length and feed particle size was evaluated. Coarser material of iron ore 
consisting of better grade ( $>64 \% \mathrm{Fe}$ ) was put to form a bed in the jig compartment. The compartment was filled with three fourth bed materials and jigged for a predetermined time, which was operating under a desired water pulsation. The mixture of coarser iron particles in the bed was stratified as a result of periodic dilation of the bed through the action of pulsating currents of water. The material was then added and the stratified particles at the end of the experiments were collected as over flow and under flow, dried weighed and analyzed to calculate the product grades. The large-scale continuous jigging studies at a feed rate of 190-200 kg/hr were carried out in Harz jig using $-5+1 \mathrm{~mm}$ size material. The concentrates and tailings in jigging operations were collected, dried, weighed and analyzed for the iron values.

\section{RESULTS AND DISCUSSION}

\subsection{Characterization Studies}

The chemical analysis of the iron ore sample is shown in Table 1. The sample contains $56.5 \% \mathrm{Fe}$, which is very low-grade in nature. The major impurities are $\mathrm{SiO}_{2}$ $5.6 \%, \mathrm{Al}_{2} \mathrm{O}_{3} 6.2 \%, \mathrm{P}_{2} \mathrm{O}_{5} 0.32 \%$ and loss on ignition (LOI) $7.10 \%$. This sample can not be used either in blast furnace or sponge iron making without under going any physical beneficiation techniques. The high LOI content in the sample is due to hydroxyl bound minerals present in the sample. The results obtained on particle size analysis down to 210 micron size are shown in Table 2. It is observed that the gangue materials being fine grained and friable are preferentially accumulated in the finer sizes. However, iron values in any fraction are found to be below $60 \% \mathrm{Fe}$. The $80 \%$ passing size of the material is around $10 \mathrm{~mm}$. It has been observed that the particles below 210 micron size are $19.0 \%$ by weight. This fraction is generally discarded in Indian iron ore washing plants as tailings due to limitation of particle size and presence of high silica and alumina content in it.

\subsection{Mineralogical Studies}

Iron ore samples are hard massive, laminated, porous, biscuity and powdery in nature. The minerals like kaolinite, gibbsite, and fine grained goethite (ochreous/earth goethite) frequently occur as surface coatings of the iron ore lumps. Ore microscopic studies indicated that the hematite grains are of different types viz; microplaty, lacy and vermicular and specular hematite. The martite grains are euhedral and subhedral in nature. The precursor magnetite grains have been completely changed to martite. The martite grains have also been recrystallised to granular grains of 25-35 micron size. In many samples martite and microplaty hematite grains (max. length of $25 \mu \mathrm{m}$ ) form dense aggregates with minor amounts of voids $(<5 \%)$. Martite grains also occur as dissemination within the dense microplaty aggregates. Coarse specular hematite grains occur in the voids. Vitreous and ochreous goethites are abundant in many iron ore samples. Goethite fills up the voids and fractures partially or completely in iron ores. The sizes of voids vary from few microns to few mm across. Hematite of varying sizes and shapes occur as inclusions within the goethite. It occurs as massive mass, crusts, colloform bands and fibrous grains. Vitrous goethite is grey to dark grey in colour; ochreous/earthy goethite is black to dark grey and composed of ultra fine crystallites. The 
aluminous minerals, kaolinite and gibbsite, are fine grained and occur in intimate association with ochreous goethite.

TABLE 1: Chemical analysis of the iron ore sample

\begin{tabular}{|c|c|}
\hline Constituents & Percent \\
\hline $\mathrm{Fe}_{2} \mathrm{O}_{3}$ & 80.79 \\
\hline $\mathrm{Fe}$ & 56.5 \\
\hline $\mathrm{Al}_{2} \mathrm{O}_{3}$ & 6.2 \\
\hline $\mathrm{SiO}_{2}$ & 5.6 \\
\hline $\mathrm{P}_{2} \mathrm{O}_{5}$ & 0.32 \\
\hline $\mathrm{LOI}$ & 7.1 \\
\hline
\end{tabular}

TABLE 2: Size and iron analysis of the sample

\begin{tabular}{|l|l|l|l|l|l|l|l|}
\hline $\begin{array}{l}\text { Size, } \\
\mathrm{mm}\end{array}$ & $\begin{array}{l}\text { Weight, } \\
\%\end{array}$ & $\begin{array}{l}\mathrm{Fe}, \\
\%\end{array}$ & $\begin{array}{l}\mathrm{Fe}_{2} \mathrm{O}_{3}, \\
\%\end{array}$ & $\begin{array}{l}\mathrm{SiO}_{2}, \\
\%\end{array}$ & $\begin{array}{l}\mathrm{Al}_{2} \mathrm{O}_{3}, \\
\%\end{array}$ & $\begin{array}{l}\mathrm{P}_{2} \mathrm{O}_{5}, \\
\%\end{array}$ & $\begin{array}{l}\text { LOI, } \\
\%\end{array}$ \\
\hline$-30+18$ & 18.7 & 57.1 & 81.62 & 3.57 & 4.24 & 0.24 & 9.17 \\
\hline$-18+5$ & 23.7 & 59.7 & 85.3 & 3.85 & 4.23 & 0.22 & 6.2 \\
\hline$-5+1$ & 27.3 & 58.5 & 83.65 & 4.2 & 4.5 & 0.24 & 8.4 \\
\hline$-1+0.21$ & 11.3 & 57.9 & 82.8 & 4.5 & 4.0 & 0.26 & 8.2 \\
\hline-0.21 & 19.0 & 48.2 & 68.92 & 9.3 & 11.62 & 0.37 & 9.4 \\
\hline
\end{tabular}

\subsection{Sink and Float Studies}

The sink and float studies of different closed fractions at three sp. gravities viz. $2.8,3.1$ and 3.3 were carried out to evaluate the liberation characteristics of iron and gangue particles. The results are shown in Table 3. It has been observed that, in case of heavy liquid of 2.8 sp.gravity very little floats could be observed indicating less free silica or alumina minerals at this density. The total float of $11.1 \%$ with $41.8 \% \mathrm{Fe}$ could be obtained at 2.8 sp.gravity. This indicates that there is some liberated gangue material associated with the sample. In case of the dense liquid of $3.1 \mathrm{sp}$. gravity, the percentage of floats in all the size fractions has increased and gone upto $22.2 \%$ with $46.0 \% \mathrm{Fe}$. The results at 3.1 sp.gravity have indicated that around $66.1 \%$ by weight of heavy material at $63.66 \% \mathrm{Fe}$ could be obtained. The results of sink float studies using the heavy liquid of $3.3 \mathrm{sp}$. gravity show that the weight of float fraction has slightly enhanced in comparison to $3.1 \mathrm{sp}$. gravity. The results of the studies at $3.3 \mathrm{sp}$. gravity have indicated that an iron grade of $64.21 \% \mathrm{Fe}$ could be obtained at a yield of $61.8 \%$. Mineralogically, the float samples consisted of porous laterites and lateritised iron ores and minor amounts of free 
quartz and shale particles. The minerals identified (by microscopy and XRD studies) in the float samples are goethite, hematite, quartz, kaolinite and gibbsite.

\section{TABLE-3: Summary of sink and float studies}

\begin{tabular}{|l|l|l|}
\hline Specific gravity & Weight, $\%$ & Fe, $\%$ \\
\hline 2.8 Float & 11.1 & 41.8 \\
\hline 3.1 Float & 22.2 & 46.0 \\
\hline 3.3 Float & 26.4 & 47.6 \\
\hline 3.3 Sink & 61.8 & 64.5 \\
\hline
\end{tabular}

Jigging, an effective gravity concentration technique, was therefore undertaken in the laboratory to beneficiate this type of iron ore. The effect of water velocity on particle separation in mineral jig was studied by taking three closed sized feed sample, viz. $-5+1$ $\mathrm{mm},-4+1 \mathrm{~mm}$ and $-1+0.21 \mathrm{~mm}$.

Separation efficiencies were calculated for all the amplitude varied with regard to three sizes. The separation efficiency is calculated based on the iron content in feed, jig concentrate and jig tailings. The separation efficiency is calculated as

Separation efficiency, $\mathrm{SE}=\mathrm{R} \times \mathrm{E}$ where $\mathrm{E}$ is the enrichment and $\mathrm{R}$ is the recovery. Enrichment is donated by

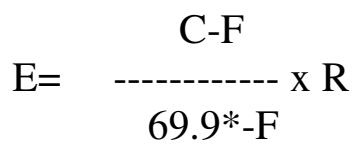

Where $\mathrm{C}, \mathrm{F}$ are the concentration of iron in jig concentrates and tailings. The recovery of the jig product is calculated based on the formula

$\mathrm{C}(\mathrm{F}-\mathrm{T})$

$\mathrm{R} \%=$

$\mathrm{F}(\mathrm{C}-\mathrm{T})$

Where $\mathrm{T}$ is the concentration of iron in Tailings

* Theoretically maximum iron percent obtainable.

\subsection{Effect of Water Velocity}

The effect of water velocity on three different particle size viz. $-5+1 \mathrm{~mm},-4+1$ $\mathrm{mm}$ and $-1+0.21 \mathrm{~mm}$ at a constant stroke length is shown in Figure 1. The separation efficiency of each particle size is calculated by using the above formula. It can be inferred that the separation efficiency is more in case of finer sizes i.e.- $1+0.21 \mathrm{~mm}$, which is due to better liberation of the particles. The water velocity of $4-5 \mathrm{~cm} / \mathrm{sec}$ is needed to separate the iron particles from the associate gangues. Further increase in water velocity has not much impact with regard to the efficiency of separation. Figure 2 indicates the effect of water velocity at the particle size of $-5+1 \mathrm{~mm}$ on different amplitudes. It has been 
observed that separation efficiency is better at higher amplitude. It has been also inferred that higher amplitude is needed to lift the coarse particles.
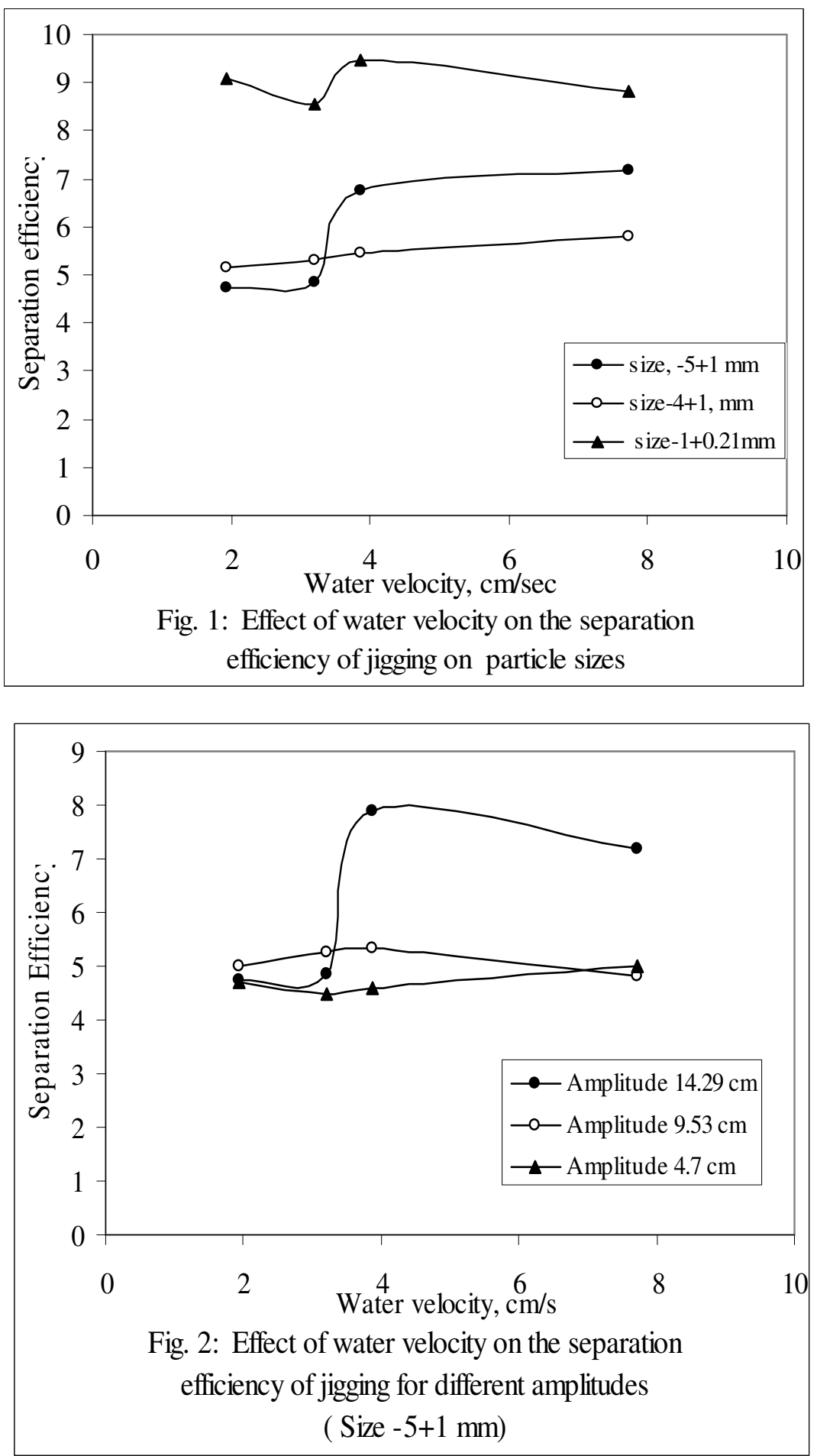


\subsection{Large Scale Jigging Studies}

The large-scale jigging studies were carried out on a composite sample of $-5+1$ $\mathrm{mm}$ material using Denver Harz Jig. The iron ore of slightly coarser size was used as the bed material. The sample was fed at $150-200 \mathrm{~kg} / \mathrm{hr}$ with a water rate of 10 liters/minute. The samples of feed, concentrate and tailings were collected simultaneously after attaining the steady state of the jig. The results of these studies are shown in Table 4. It was possible to obtain an iron grade of $63.71 \% \mathrm{Fe}$ with $73 \%$ yield. The jig tailings contain around $47 \% \mathrm{Fe}$, which can be easily rejected without carrying out any further treatment. Thus a good iron concentrate could be obtained by processing the iron ore fines by jigging technique. The complete chemical analysis of the large-scale jig concentrate and tailings are shown in Table 5. The jig tailings contain around $47 \% \mathrm{Fe}$ with high alumina (13.78\%) and silica contents (6.97\%).

Table 4: Continuous large scale Jigging studies

Particle size $-5+1 \mathrm{~mm}$, self bed, water rate: 10 litres/minute

\begin{tabular}{|l|l|l|}
\hline $\begin{array}{l}\text { Experiment } \\
\text { Nos. }\end{array}$ & $\begin{array}{l}\text { Jig } \\
\text { concentrate, } \\
\text { Fe\% }\end{array}$ & $\begin{array}{l}\text { Jig } \\
\text { tailings, } \\
\mathrm{Fe} \%\end{array}$ \\
\hline 1 & 63.1 & 40.91 \\
\hline 2 & 63.4 & 46.49 \\
\hline 3 & 64.6 & 45.43 \\
\hline 4 & 63.4 & 44.53 \\
\hline 5 & 63.1 & 46.5 \\
\hline 6 & 63.8 & 46.5 \\
\hline 7 & 63.8 & 45.43 \\
\hline 8 & 64.1 & 46.49 \\
\hline 9 & 64.6 & 45.4 \\
\hline 10 & 63.1 & 43.45 \\
\hline
\end{tabular}

Average Concentrate grade: $\mathrm{Fe} \%=63.70$

Average Tailings grade $: \mathrm{Fe} \%=47.1$

Average Feed grade

Average yield \%

$\mathrm{Fe} \%=59.4$

$=73.0$

Fe, Recovery, \%

$=78.6$ 
Table 5: Complete chemical analysis of the Jig concentrate and Tailings

\begin{tabular}{|l|c|c|}
\hline Constituents & $\begin{array}{c}\text { Jig Concentrate, } \\
\%\end{array}$ & $\begin{array}{c}\text { Jig Tailings, } \\
\%\end{array}$ \\
\hline $\mathrm{Fe}_{2} \mathrm{O}_{3}$ & 90.24 & 67.35 \\
\hline $\mathrm{Fe}(\mathrm{T})$ & 63.11 & 47.1 \\
\hline $\mathrm{Al}_{2} \mathrm{O}_{3}$ & 3.15 & 13.78 \\
\hline $\mathrm{SiO}_{2}$ & 2.41 & 6.97 \\
\hline $\mathrm{P}_{2} \mathrm{O}_{5}$ & 0.075 & 0.263 \\
\hline $\mathrm{LOI}$ & 4.0 & 11.6 \\
\hline
\end{tabular}

\subsection{Mineralogy of Jig Concentrate and Tailings}

Jig concentrate and tailing samples were subjected to detail mineralogical studies to know the distribution of different phases in both the fractions. The sample of $-1+0.21$ $\mathrm{mm}$ fraction was selected as they are better liberated fractions. The jig concentrate and tailing samples were wet sieved into different size fraction, viz., $-1+0.701 \mathrm{~mm}$, $-0.701+0.500 \mathrm{~mm},-0.500+0.350 \mathrm{~mm}$ and $-0.350+0.210 \mathrm{~mm}$. Each fraction was mounted in epoxy resin and polished for microscopic observation. The particles were classified into (a) free hematite, (b) free vitreous goethite, (c) free earthy goethite, (d) locked hematite-vitreous goethite and (e) locked hematite-earthy goethite. The free grains contained max. $5 \%$ of other mineral phase. The locked hematite particles were classified into different grades, viz., particles with 5-20, 20-40, 40-60, 60-80 and 80-95\% vitreous or earthy goethite. The data are presented in Table 6 . Some of the features of hematite and goethite are shown in Figs. 3 to 6.

Quantitative mineralogical data indicate that the concentrates contain significantly more amounts of total hematite compared to tailings. Conversely, tails have more amounts of goethite. The particles in the tailings are porous and composed predominantly of laterites some of which are aluminous variety (aluminous late rites). The total hematite percent in three different jig concentrate size fractions are 49.37\%, 48.95 and 39.7\%, respectively, compared to $7.46 \%, 8.42 \%$ and $12.55 \%$ in jig tailing sample.

Table -6: Quantitative mineralogy of jig concentrate and tailing samples

\begin{tabular}{|l|lr|lr|lr|}
\hline Size, Microns & $\begin{array}{l}\mathbf{7 0 1 - 5 0 0} \\
\text { Conc }\end{array}$ & Tail & $\begin{array}{l}\mathbf{5 0 0 - 3 5 0} \\
\text { Conc }\end{array}$ & Tail & $\begin{array}{l}\text { 35-210 } \\
\text { Conc }\end{array}$ & Tail \\
\hline Nature & 12.27 & $\mathrm{Tr}$ & 20.86 & Tr & 16.93 & 2.3 \\
\hline Free hematite & 20.02 & 68.44 & 26.18 & 66.7 & 34.58 & 41.45 \\
\hline Free vitreous goethite & 1.81 & 10.87 & 3.78 & 11.1 & 6.59 & 35.6 \\
\hline Free earthy goethite & 16.66 & 6.46 & 14.3 & 3.44 & 10.69 & 1.93 \\
\hline Locked hematite- VG & 49.25 & 14.22 & 34.87 & 18.76 & 31.21 & 18.71 \\
\hline Locked hematite- OG & 100 & 100 & 100 & 100 & 100 & 100 \\
\hline Total Hem & 49.37 & 7.46 & 48.9 & 8.42 & 39.7 & 12.55 \\
\hline Wt.\% & 13.68 & 4.20 & 26.72 & 15.6 & 35.1 & 638.61 \\
\hline
\end{tabular}

VG-Vitreous goethite, OG- Ochreous goethite 


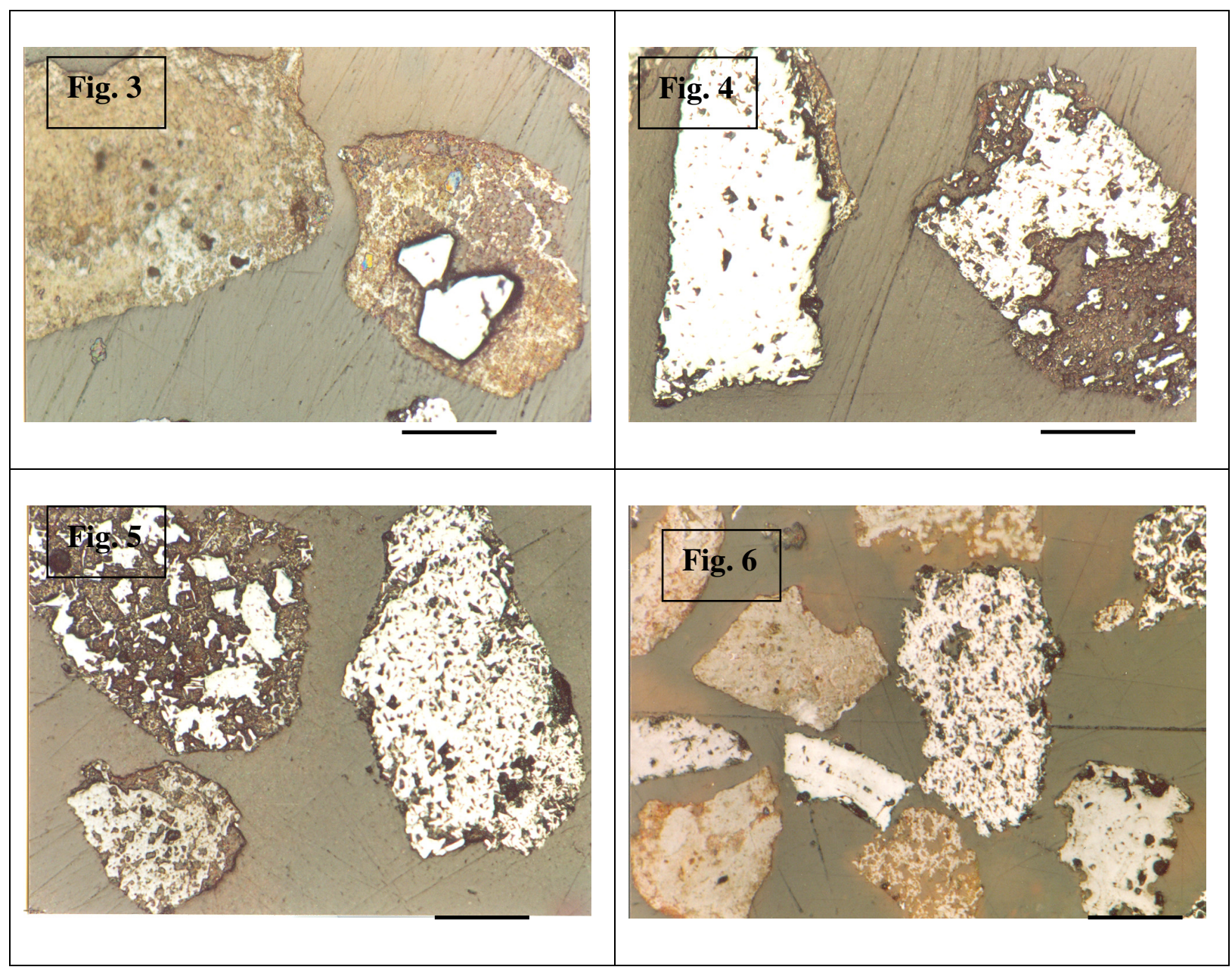

Fig.3: Photomicrograph showing free microporous vitreous goethite and locked martiteochreous goethite. Scale bar: $70 \mu \mathrm{m}$.

Fig. 4: Two types of locked particles: one is with more than $90 \%$ hematite (dense aggregates of recrystallised martite) and other is about $50 \%$ hematite and $50 \%$ ochreous goethite. Scale bar: $70 \mu \mathrm{m}$.

Fig. 5: Photomicrographs showing different types of particles: Free hematite with densely packed microplaty hematite, locked hematite and free vitreous goethite. Scale bar: $70 \mu \mathrm{m}$.

Fig. 6: Photomicrograph showing free hematite particle consisting of microplaty hematite grains, free ochreopus and vitreous goethite particles. Scale bar: $70 \mu \mathrm{m}$. 


\section{CONCLUSIONS}

The results of this investigation clearly established that effective separation of iron ore concentrate from low grade iron ore sample of Orissa by jigging operation is possible. The effectiveness of separation is greatly influenced by the water velocity, particle size and amplitude. The separation efficiency is better in case of fine particle size because of better liberation of the iron particles from the associated gangues. The mineralogical studies supported the above findings that more of hematite particle are reported into the jig concentrate compared to the jig tailings. The results of the large scale investigations have shown that it is possible to obtain $63.71 \% \mathrm{Fe}$ with $73 \%$ yield which is almost close to theoretical yield obtained by sink and float studies. The products can be utilized in the steel plant as a sinter feed material

\section{ACKNOWLEDGEMENT}

The authors are thankful to Prof. B.K.Mishra, Director, Institute of Minerals and Materials Technology, Bhubaneswar, for his encouragement and kind permission to publish this paper.

\section{REFERENCES}

[1] Rong, X Rui and Lyman, Geoffrey J., 1992, Fuel, vol. 71, 1, pp. 115.

[2] Xia, Y.K. and Peng, F.F., 2007, Mineral Engineering, vol 20,2, pp.113.

[3] Tsunekawa, M., Naoi, B., Takubo, T., Hirajima, T., Hiroyoshi, N., Otani, M., Miyamoto, M., and Ito, M., 2001,Jig separation of plastic waste used in copy machines, Proceeding 7th International Symposium on East Asian Resources Recycling Technology, The Korean Institute of Resources Recycling, pp592.

[4] Tsunekawa, Masami., Naoi, Banryu., Ogawa, Shingo., Hori, Kunihiro., Hiroyoshi, Naoki., Ito, Masazumi and Hirajim, Tsuyoshi, 2005, Int. Journal of Mineral Processing vol, 76, 1-2, 4, pp67-74.

[5] Olubambi, P.A. and Potgietez, J.H. 2005, Journal of Mineral and Material characterization and Engineering, vol.4, No.1, pp21.

[6] Sripriya, R. and. Murty, Ch. V.G.K., 2005, Int. Journal of Mineral Processing, vol. 75, 1- 2, pp123.

[7] Yang, David C., Reenan, Ricus van. and Bhimsan, Vima, 2003, Journal of Minerals and Material Characterization \& Engineering. vol. 2, No.2, pp137.

[8] Mukherjee, A.K. and Mishra, B.K., 2006, Mineral Engineering, vol 19, 9, pp.952.

[9] Mukherjee, A.K. and Mishra, B.K. 2006, Int. Journal of Mineral Processing vol.81, 3, pp.187.

[10] Mishra, B.K. and Adhikari, B. 1999, Mineral Engineering. vol. 12, 12, pp.1469. 